\title{
Electrochemical Determination of Metronidazole in Tablet Samples Using Carbon Paste Electrode
}

\author{
Yosef Nikodimos and Meareg Amare \\ Department of Chemistry, Bahir Dar University, P.O. Box 79, Bahr Dar, Ethiopia \\ Correspondence should be addressed to Meareg Amare; amaremeareg@yahoo.com
}

Received 7 December 2015; Revised 11 January 2016; Accepted 8 March 2016

Academic Editor: Sibel A. Ozkan

Copyright (c) 2016 Y. Nikodimos and M. Amare. This is an open access article distributed under the Creative Commons Attribution License, which permits unrestricted use, distribution, and reproduction in any medium, provided the original work is properly cited.

\begin{abstract}
Cyclic voltammetric investigation of metronidazole at carbon paste electrode revealed an irreversible reduction peak centered at about $-0.4 \mathrm{~V}$. Observed peak potential shift with $\mathrm{pH}$ in the range 2.0 to 8.5 indicated the involvement of protons during the reduction of metronidazole, whereas the peak potential shift with scan rate in the range $10-250 \mathrm{mV} / \mathrm{s}$ confirmed the irreversibility of the reduction reaction. A better correlation coefficient for the dependence of peak current on the scan rate than on the square root of scan rate indicated an adsorption controlled kinetics. Under the optimized method and solution parameters, an excellent linearity between the reductive peak current and the concentration of metronidazole was observed in the concentration range $1.0 \times 10^{-6}$ to $5.0 \times 10^{-4} \mathrm{M}$ with a correlation coefficient, method detection limit (based on $s=3 \sigma$ ), and limit of quantification of $0.999,2.97 \times$ $10^{-7} \mathrm{M}$ and $9.91 \times 10^{-7} \mathrm{M}$, respectively. Good recovery results for spiked metronidazole in tablet samples and selective determination of metronidazole in tablet formulations in the presence of selected potential interferents such as rabeprazole, omeprazole, and tinidazole confirmed the potential applicability of the developed method for the determination of metronidazole in real samples like pharmaceutical tablets.
\end{abstract}

\section{Introduction}

Metronidazole (2-methyl-5-nitroimidazole-1-ethanol) belongs to a group of nitroimidazole drugs used in therapeutics mainly in the treatment of infections caused by susceptible organisms, particularly anaerobic bacteria (Bacteroides, Fusobacterium, Campylobacterium, and Clostridium) and protozoa (Trichomonas, Treponema, and Histomonas) [1,2]. It can kill or inhibit the majority of anaerobic bacteria when the metronidazole concentration in serum is in the range of 2 to $8 \mathrm{mg} / \mathrm{mL}$ [3].

Due to its antimicrobial activity, rapid bacterial killing, good tissue penetration, low cost, and limited adverse ejects, metronidazole (MTZ) is the drug of choice for prophylaxis and treatment of patients with Crohn's disease and ulcerative colitis to prevent infectious complications $[4,5]$.

The pharmacokinetic and pharmacodynamic properties of the drug are favorable, and it is available as oral, intravenous, vaginal, and topical formulations. After oral administration, metronidazole is well absorbed, and its peak plasma concentrations occur 1-2 $\mathrm{h}$ after administration $[1,4]$.
In accordance with the international guidelines, metronidazole is also a component of multidrug regimens (e.g., in combination with omeprazole, rabeprazole, and amoxicillin) for therapy of Helicobacter pylori infections, which is a major cause of gastritis and a risk factor for stomach cancer [4, 6].

However, high doses and long-term systemic treatment with metronidazole are associated with the development of leucopenia, neutropenia, increased risk of peripheral neuropathy, and toxicity of the central nervous system. In clinical studies, where high doses of metronidazole were used during radiation treatment for cancer, an overdose was believed to increase the risk of seizures or nerve problems in the hands and feet [7]. The side effects may vary from patient to patient depending on the overall health of the patient. The medication is most likely to cause problems in the case of overdose when it is taken by mouth or by IV, rather than applied to the skin or used vaginally [8].

High performance liquid chromatography [9-11], titrimetric method [12], and spectrophotometry [13] are the conventional methods reported for the determination of metronidazole in pharmaceutical sample. However, most of these 
methods are time-consuming, tedious, environmental nonfriendly, and expensive and require trained technicians [14].

On the contrary, electrochemical methods are promising alternatives for the determination of electroactive species, because of their inherent advantages of simplicity, ease of miniaturization, high sensitivity, and relatively low cost $[15$, 16]. Limited works have been reported on the electrochemical determination of metronidazole in pharmaceutical and clinical matrices using mercury electrode $[17,18]$, DNA-modified glassy carbon electrode [19], composite polymer membrane electrode [20], ultratrace graphite electrode (UTE) [21], activated glassy carbon electrode [22], and MWNT/glassy carbon electrode [23]. Although the reported methods are sensitive with detection to a nanomolar level, most of them have used mercury electrode which is environmental unfriendly, while the others have used expensive electrodes. Thus, the development of a simple, cost effective, and sensitive method is needed for the determination of metronidazole in pharmaceutical formulations. Thus, square wave voltammetric determination of metronidazole in tablet samples using carbon paste electrode $(\mathrm{CPE})$ is presented in this study.

\section{Experimental}

2.1. Chemicals and Apparatus. Standard metronidazole and graphite powder (British Drug Houses Ltd., UK), metronidazole tablets of three brands, two Ethiopian brands (Addis Pharmaceuticals Factory (APF) and Ethiopian Pharmaceuticals factory (EPHARM)) and the third is an Indian brand, rabeprazole and tinidazole tablets (APF), omeprazole tablet (EPHARM), paraffin oil (Abron Chemicals Ltd.), phosphoric acid (EPHARMECOR), and boric acid, glacial acetic acid, and sodium hydroxide (Blulux Laboratories Ltd.) were used. All chemicals were of analytical grade that they were used without further purification.

A BAS 100B, electrochemical analyzer (Bioanalytical Systems (BAS), USA) with three-electrode system, carbon paste electrode as working electrode, platinum wire as auxiliary electrode, and $\mathrm{Ag} / \mathrm{AgCl}$ as reference electrode, was used. Jenway model $3310 \mathrm{pH}$ meter and an electronic balance (Denver Instrument) were used to measure the $\mathrm{pH}$ of the buffer solutions and the mass of different chemicals, respectively.

\subsection{Procedure}

2.2.1. Preparation of Standard Solution. Britton Robinson buffer solution (BRB solution) in the $\mathrm{pH}$ range $2.0-12.0$ was prepared from a mixture $(0.1 \mathrm{M})$ of acetic acid, boric acid, and phosphoric acid. The $\mathrm{pH}$ of the solutions was adjusted using $1 \mathrm{M}$ sodium hydroxide solution.

A stock solution of $5 \mathrm{mM}$ standard metronidazole solution was prepared by dissolving $0.0856 \mathrm{~g}$ of metronidazole in $100 \mathrm{~mL}$ of distilled water. The required metronidazole working solutions were prepared by diluting the stock solution with the BRB solution of the appropriate $\mathrm{pH}$.

2.2.2. Pharmaceutical Tablet Sample Preparation. Metronidazole tablets (all labelled as $250 \mathrm{mg}$ per tablet) of three brands, two of which are Ethiopian (Addis Pharmaceuticals Factory
(APF) and Ethiopian Pharmaceuticals Factory (EPHARM)) and the third is an Indian factory (Aurobindo Pharmaceutical Industries), were collected from a pharmacy. Five tablet formulations of each brand were accurately weighed and ground using mortar and pestle. An adequate amount of this powder, corresponding to a stock solution of concentration $1 \times 10^{-2} \mathrm{M}$, was weighed and transferred into a $100 \mathrm{~mL}$ flask and filled to the mark with distilled water. An intermediate tablet solution of $5 \mathrm{mM}$ concentration was prepared from the tablet stock solution using distilled water as a solvent. After filtration, 35, 70 , and $88 \mu \mathrm{M}$ sample solutions were prepared from the tablet stock solution using BRB solutions for each brand of metronidazole tablet.

2.2.3. Preparation of Working Electrode. Carbon paste electrode was prepared by thoroughly mixing $1 \mathrm{~g}$ of graphite powder with paraffin oil in a ratio of $72 \%(\mathrm{w} / \mathrm{w})$ graphite powder and $28 \%(\mathrm{w} / \mathrm{w})$ paraffin oil [24]. The mixture was homogenized with mortar and pestle for 30 minutes and allowed to stand for $24 \mathrm{hrs}$. The homogenized paste was packed into the tip of a plastic tube of diameter $3.5 \mathrm{~mm}$ (chewing gum stick bought from ordinary shop). After copper wire was inserted from the backside of the plastic tube to provide electrical contact, the electrode was made ready for use after the surface of the electrode was smoothed manually against a smooth white paper until a shiny surface is emerged.

2.3. Method of Analysis. Cyclic voltammetry in the potential window +500 to $-1200 \mathrm{mV}$ was used for the investigation of the electrochemical behavior of standard metronidazole at carbon paste electrode. The effects of scan rate in the range of 10 to $250 \mathrm{mV} / \mathrm{s}$ and $\mathrm{pH}$ in the range 20 to 120 on the peak potential and peak current of metronidazole were also studied using cyclic voltammetry. For the quantitative determination of metronidazole using carbon paste as a working electrode, a square wave voltammetry in the range -100 to $-1100 \mathrm{mV}$ was employed. Linear calibration curve for the dependence of square wave peak current on the concentration of standard metronidazole was obtained. Moreover, the metronidazole content of different brands of metronidazole tablets was determined. Recovery results of spiked standard metronidazole in tablet solutions, interference study results, method detection limit, linear range, and precession of the results obtained were used to validate the applicability of the developed method for the determination of metronidazole in pharmaceutical formulations.

\section{Results and Discussion}

\subsection{The Cyclic Voltammetric Investigation of Metronidazole at CPE}

3.1.1. Electrochemical Behavior of Metronidazole. Figure 1 presents the cyclic voltammograms of CPE in BRB solution ( $\mathrm{pH} 2.0)$ in the presence and absence of $1 \mathrm{mM}$ metronidazole. In the absence of metronidazole, a weak and broad reductive peak that appeared between -500 and $-1050 \mathrm{mV}$ was ascribed to the oxygen reduction (curve (a) of Figure 1). On the contrary, a well-defined, intensive, and sharp reductive peak 


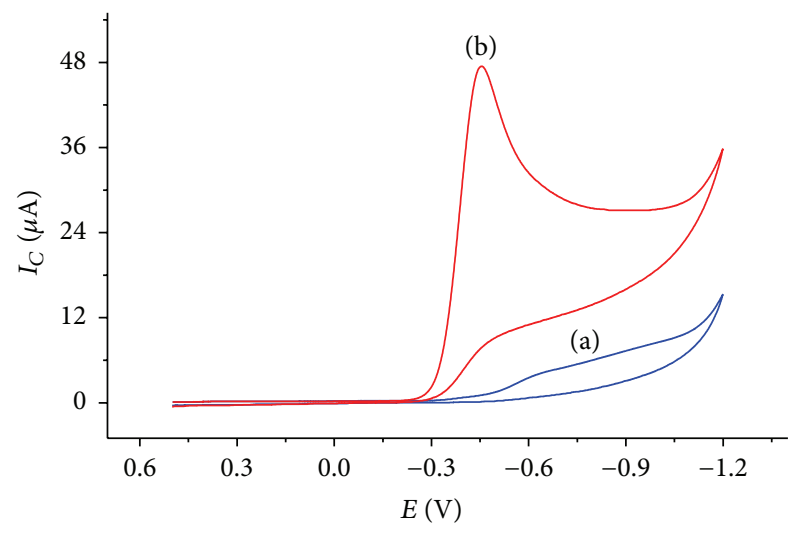

FIGURE 1: Cyclic voltammograms of CPE in BRB solution containing (a) no MTZ and (b) $1 \mathrm{mM} \mathrm{MTZ}$ at pH 2.0 and scan rate $100 \mathrm{mV} / \mathrm{s}$.

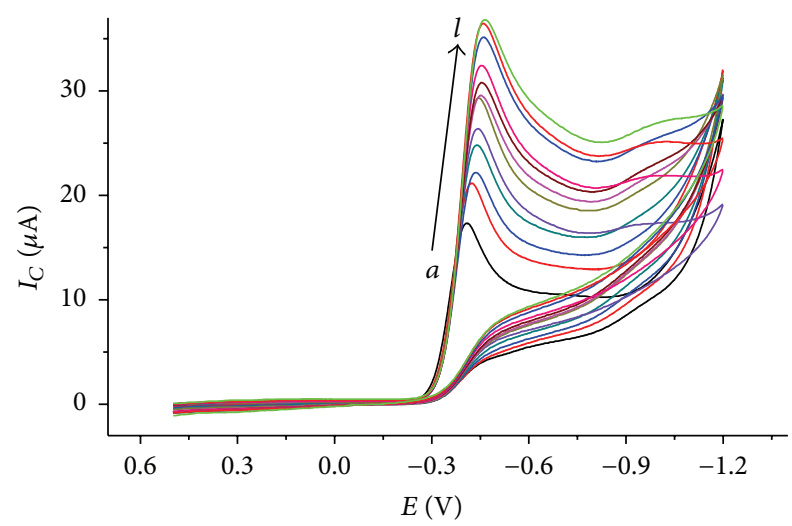

FIGURE 2: Cyclic voltammograms of $1 \mathrm{mM}$ metronidazole in BRB solution ( $\mathrm{pH}$ 2.0) using CPE at various scan rates ( $a-l: 10,20,40,60$, $80,100,125,150,175,200,225$, and $250 \mathrm{mVs}^{-1}$, resp.).

centered at $-450 \mathrm{mV}$ (curve (b) of Figure 1) was observed in the presence of $1 \mathrm{mM}$ metronidazole indicating an irreversible reduction of metronidazole at $\mathrm{CPE}$.

3.1.2. Effect of Scan Rate. The effects of scan rate on the reduction peak current and peak potential of metronidazole were studied. Figure 2 describes the cyclic voltammograms of $1 \mathrm{mM}$ metronidazole at scan rate range of $10-250 \mathrm{mV} / \mathrm{s}$. Cathodic peak potential shifted to a larger negative potential value confirming the irreversibility of the reduction reaction of MTZ at CPE [25].

In order to investigate whether the reduction process of metronidazole at CPE is predominantly diffusion controlled or adsorption controlled process, the correlation coefficients for the linear plots of the reductive peak current versus the scan rate and reductive peak current versus the square root of scan rate were compared (figure not shown). In contrast, a better correlation coefficient for the dependence of reductive peak current on the scan rate $(r=0.999)$ than on the square root of scan rate $(r=0.993)$ indicated that the reduction of metronidazole at $\mathrm{CPE}$ is governed by both surface-adsorption and diffusion kinetics though it is predominantly surfaceconfined kinetics [26].
Furthermore, the number of electrons transferred (n) for the surface-confined irreversible process was estimated employing the following equations $[25,27]$ :

$$
\begin{aligned}
I_{P C} & =\frac{(\alpha n) n^{2} F^{2} \Gamma \nu}{2.718 R T}, \\
\left|E_{P}-E_{P / 2}\right| & =1.85 \frac{R T}{\alpha n F} \mathrm{~V}=\frac{0.048}{\alpha n} \mathrm{~V} \text { at } 25^{\circ} \mathrm{C}, \\
\Gamma & =\frac{Q}{n F A},
\end{aligned}
$$

where $I_{P}$ is peak current, $v$ is scan rate, $\Gamma$ is surface concentration of the electroactive species in $\mathrm{mol} \mathrm{cm}^{-2}, A$ is electrochemical active electrode surface area in $\mathrm{cm}^{2}, \alpha$ is electron transfer coefficient, $R$ is the universal gas constant $\left(8.314 \mathrm{~J} \mathrm{~K}^{-1} \mathrm{~mol}^{-1}\right), T$ is the Kelvin temperature, $F$ is Faraday constant $\left(9,6485 \mathrm{C} \mathrm{mol}^{-1}\right), E_{P}$ is peak potential, $E_{P / 2}$ is half peak potential, and $Q$ is the charge consumed in coulomb obtained by integrating the peak area. Taking the voltammogram at a scan rate of $100 \mathrm{mV}$ in Figure 2, $\alpha n$ value estimated using (2) was calculated to be about 0.913 . Substituting $\Gamma$ term of (3) into (1), a new relation was obtained (4) from which the number of electrons transferred $(n)$ in the rate determining step was calculated to be $3.77(\approx 4)$ which is in agreement with earlier reported work [17]

$$
n=\frac{2.718 I_{P} R T}{(\alpha n) F Q v} .
$$

The value of $\alpha$ was then calculated to be 0.228 , still confirming the irreversibility of the reduction of MTZ at CPE.

Plot of reductive peak potential $\left(E_{P C}\right)$ against the logarithm of scan rates $(\ln v)$ showed linear dependence with a linear regression equation and correlation coefficient of $E_{P C} / \mathrm{V}=-0.37356-0.026157 \ln \nu / \mathrm{Vs}^{-1}$ and $r=0.999$, respectively (figure not shown), from which the standard rate constant value for an irreversible reductive reaction was calculated using the following equation [28]:

$$
E_{P}=E^{o}+\frac{R T}{\alpha n F} \ln \left(\frac{R T k_{0}}{\alpha n F}\right)-\frac{R T}{\alpha n F} \ln \nu,
$$

where $E_{P}$ is the peak potential, $E^{o}$ is the formal potential, $\alpha$ is the electron transfer coefficient, $k_{0}\left(\mathrm{~s}^{-1}\right)$ is the electrochemical rate constant, and the other parameters have their usual meanings.

After calculating $E^{o}$ from the linear regression equation of the graph of $E_{P}$ versus $v$ (figure not shown) [29], the value of $k_{0}$ was calculated from the intercept of the plot of $E_{P}$ versus $\ln v$ (figure not shown) to be $280.38 \mathrm{~s}^{-1}$

$$
E^{o}+\frac{R T}{\alpha n F}\left[\ln \left(\frac{R T k_{0}}{\alpha n F}\right)\right]=-0.3736 \mathrm{~V} .
$$

3.1.3. Effect of Solution $\mathrm{pH}$. The effect of $\mathrm{pH}$ on the reductive peak current and peak potential of metronidazole at CPE was further studied. BRB solutions with $\mathrm{pH}$ values varying from 2.0 to 12.0 were used to investigate its effect on the reduction 


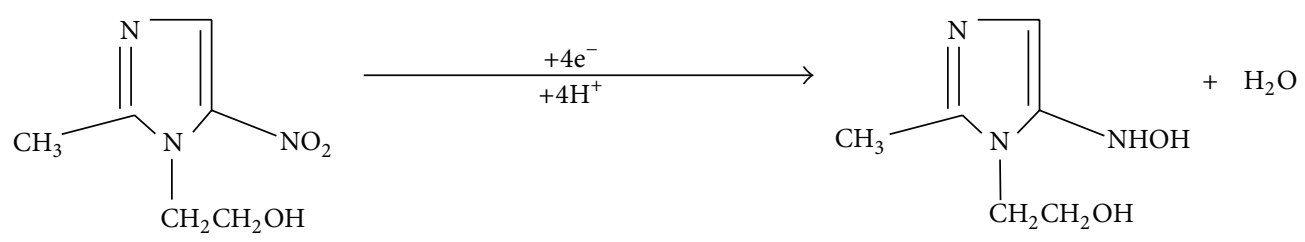

SCHEME 1: The proposed reaction mechanism of metronidazole at CPE.

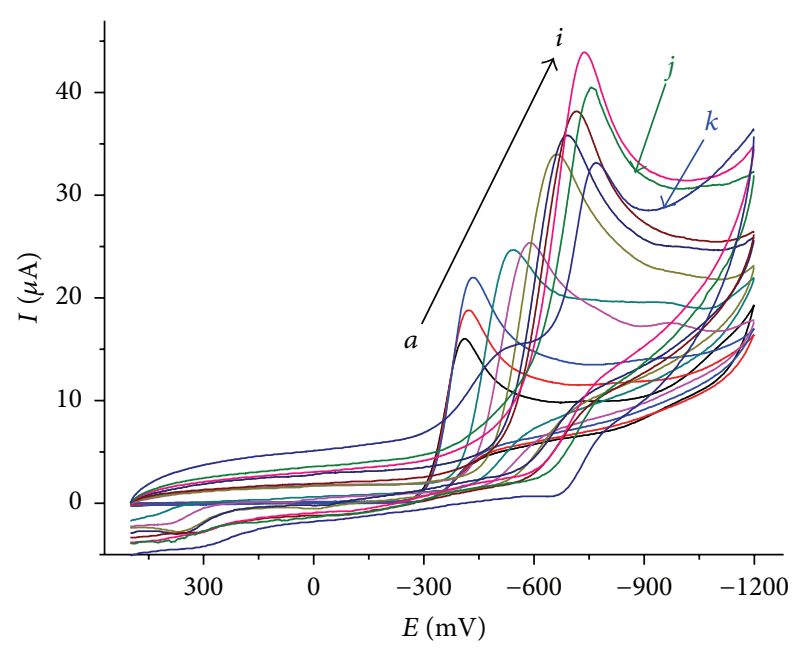

FIGURE 3: Cyclic voltammograms of $1 \mathrm{mM}$ MTZ in BRB solution of different $\mathrm{pH}$ values $(a-k: 2.0,2.5,3.5,4.0,4.5,5.0,6.0,6.5,7.0,7.5$, and 8.0 , resp.). Scan rate: $100 \mathrm{mV} / \mathrm{s}$.

of metronidazole at carbon paste electrode. The results revealed that voltammetric responses were strongly $\mathrm{pH}$ dependent in the acidic and neutral region in contrast to the alkaline medium which was in agreement with most of the electrochemical methods reported. A peak potential independent of $\mathrm{pH}$ in the alkaline medium could be attributed to the unavailability of protons that promote the reduction of MTZ at pHs larger than its pka value. Figure 3 represents cyclic voltammograms of $1 \mathrm{mM}$ MTZ in the region where its reduction is $\mathrm{pH}$ dependent ( $\mathrm{pHs}$ 2.0-8.0). A well-defined irreversible cathodic peak was observed in the entire buffer system at the CPE.

The effect of $\mathrm{pH}$ on the peak current in the studied $\mathrm{pH}$ range was investigated (Figure 4(a)). The cathodic peak current increased sharply from $\mathrm{pH} 2.0$ to 7.0 beyond which it started to decrease. Thus, $\mathrm{pH} 7.0$ was selected as the optimum $\mathrm{pH}$ for the subsequent experiments which is in agreement with previous works [16].

With increasing solution $\mathrm{pH}$ up to 8.0, a peak potential shift in the negative potential direction was observed indicating the involvement of protons during the reduction reaction of metronidazole in acidic and neutral media (Figure 3). This trend was in agreement with reported works [16-18]. A linear dependence of peak potential on solution $\mathrm{pH}$ in the $\mathrm{pH}$ range 2.0-8.0 (Figure 4(b)) with a linear regression equation and correlation coefficient of $E_{P C}(\mathrm{mV})=-291.26-$ $64.36 \mathrm{pH}$ and $r=0.999$, respectively, was observed. A slope of

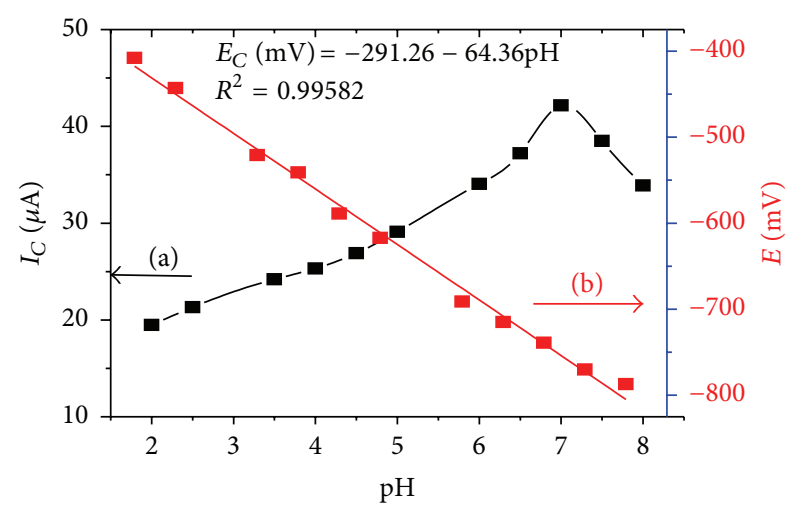

FIGURE 4: Plot of reductive (a) peak current and (b) peak potential versus $\mathrm{pH}$ for $1 \mathrm{mM}$ MTZ in $0.1 \mathrm{M}$ BRB solution of different $\mathrm{pH}$ values at CPE. Scan rate: $100 \mathrm{mV} / \mathrm{s}$.

$64.36 \mathrm{mV} / \mathrm{pH}$ typically suggested that the number of protons taking part in the reaction is similar to the number of electrons that participated in the rate determining step. Hence, a reaction mechanism involving four electrons and four protons was proposed (Scheme 1).

3.2. Quantitative Determination of Metronidazole in Pharmaceutical Formulations. Square wave voltammetry (SWV), which is one of the most sensitive voltammetric techniques, was used for the quantitative determination of metronidazole in tablet samples.

Figure 5 presents the square wave voltammograms of $\mathrm{CPE}$ in $\mathrm{pH} 7.0 \mathrm{BRB}$ solution containing no (a) and $1 \mathrm{mM}$ metronidazole (b). As can be seen from the figure, no peak is observed at CPE in the buffer solution containing no MTZ (curve (a) of Figure 5). In contrast, the same working electrode in $\mathrm{pH}$ 7.0 BRB solution containing $1 \mathrm{mM}$ MTZ resulted in an enhanced reductive peak (curve (b) of Figure 5).

3.2.1. Linear Range and Limit of Detection. Under the optimum experimental conditions $(\mathrm{pH}$, accumulation potential $\left(E_{\text {acc }}\right)$, accumulation time $\left(t_{\text {acc }}\right)$, SWV frequency, amplitude, and step potential of $7.0,-500 \mathrm{mV}, 25 \mathrm{~s}, 30 \mathrm{~Hz}, 50 \mathrm{mV}$, and $10 \mathrm{mV}$, resp.), the dependence of square wave voltammetric peak current on the concentration of MTZ and the inherited sensitivity of the method were investigated in the range $1 \times$ $10^{-6}-5 \times 10^{-4} \mathrm{M}$. Figure 6 shows square wave voltammograms of various concentrations of MTZ corrected for background.

Inset of Figure 6 presents the plot of the reductive peak current as a function of the concentration of MTZ. The limit of detection (LOD) and limit of quantification (LOQ) 
TABLE 1: Amount of MTZ detected in three brands of drug samples using the developed method.

\begin{tabular}{|c|c|c|c|c|c|c|}
\hline \multirow{2}{*}{ Tablet } & \multirow{2}{*}{ Solution } & \multirow{2}{*}{ Expected $/ \mu \mathrm{M}$} & \multicolumn{2}{|c|}{ Detected $^{*}$} & \multirow{2}{*}{$\begin{array}{l}\text { Labelled value } \\
\text { (mg/tablet) }\end{array}$} & \multirow{2}{*}{ Measured\% } \\
\hline & & & $/ \mu \mathrm{M}$ & $/(\mathrm{mg} /$ tablet $)$ & & \\
\hline \multirow{3}{*}{ APF } & $\mathrm{a}$ & 35 & 28.789 & 205.640 & 250 & 82.256 \\
\hline & $\mathrm{b}$ & 70 & 63.125 & 225.445 & 250 & 90.178 \\
\hline & c & 88 & 86.225 & 244.957 & 250 & 97.983 \\
\hline \multirow{3}{*}{ EPHARM } & $\mathrm{a}$ & 35 & 32.573 & 232.665 & 250 & 93.066 \\
\hline & $\mathrm{b}$ & 70 & 67.178 & 239.919 & 250 & 95.968 \\
\hline & c & 88 & 87.709 & 249.175 & 250 & 99.670 \\
\hline \multirow{3}{*}{ Indian } & $\mathrm{a}$ & 35 & 32.774 & 234.103 & 250 & 93.641 \\
\hline & $\mathrm{b}$ & 70 & 63.308 & 226.099 & 250 & 90.440 \\
\hline & c & 88 & 84.965 & 241.378 & 250 & 96.551 \\
\hline
\end{tabular}

${ }^{*}$ Mean of triplicate measurements.

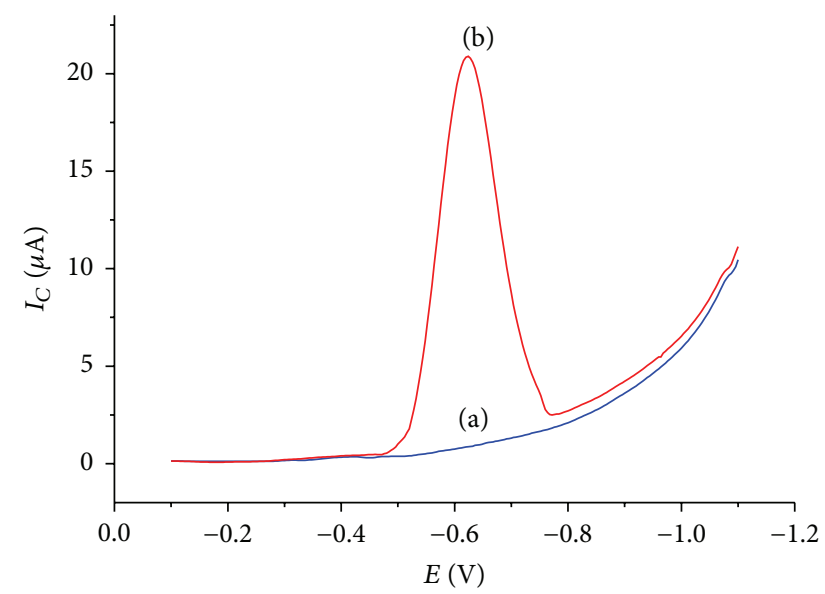

Figure 5: Square wave voltammograms of CPE in $\mathrm{pH} 7.0 \mathrm{BRB}$ solution containing (a) no MTZ and (b) 1 mM MTZ.

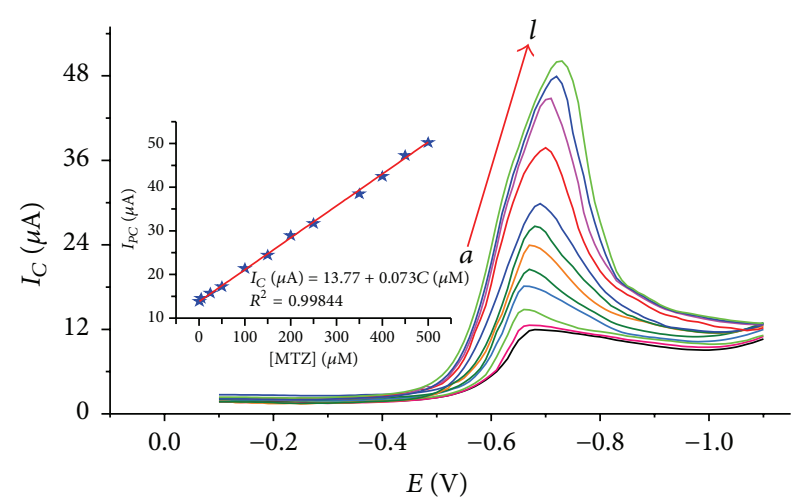

FIGURE 6: Square wave voltammograms of CPE (corrected for background) in pH 7.0 BRB solution containing MTZ of various concentrations $(a-l: 1,5,25,50,100,150,200,250,350,400$, 450 , and $500 \mu \mathrm{M}$, resp.). Inset: calibration curve of peak current versus concentration of MTZ. Experimental conditions: square wave frequency $30 \mathrm{~Hz}$, square wave amplitude $50 \mathrm{mV}$, step potential $10 \mathrm{mV}$, $E_{\mathrm{acc}}-500 \mathrm{mV}$, and $t_{\mathrm{acc}} 25 \mathrm{~s}$. calculated using (7) and (8) were found to be $2.97 \times 10^{-7}$ and $9.91 \times 10^{-7}$, respectively:

$$
\begin{aligned}
\mathrm{LOD} & =\frac{3 S}{m}, \\
\mathrm{LOQ} & =\frac{10 S}{m},
\end{aligned}
$$

where $S$ is the standard deviation for the blank $(n=8)$ and $m$ is the slope of the calibration curve.

Compared to the previously reported works which have used expensive electrode materials, CPE which is the cheapest carbon based material revealed a comparable LOD.

3.2.2. Real Sample, Recovery, and Interference Analyses. The selectivity and the accuracy and hence the validity of the carbon paste electrode for the determination of MTZ in real samples were demonstrated by evaluating its application for the determination of MTZ content in some pharmaceutical tablets. Briefly, five tablets from each brand (APF, EPHARM, and Indian) were weighed and powdered. For each brand of tablet, an amount corresponding to a stock solution of $0.01 \mathrm{M}$ concentration was weighed and transferred into $100 \mathrm{~mL}$ flask and then completed to the volume with $\mathrm{pH} 7.0 \mathrm{BRB}$ solution. Finally, 35,70 , and $88 \mu \mathrm{M}$ tablet sample solutions were prepared from the corresponding stock solution. Square wave voltammograms were recorded (figure not shown) following the outlined voltammetric procedure and optimized conditions as described earlier. Mean of triplicate measurements was taken for the determination of metronidazole in these samples.

The results for different concentrations of the three brands of tablets are summarized in Table 1. The tablet formulations for the collected brands being all $250 \mathrm{mg}$ of MTZ per tablet, the amount of MTZ detected relative to the expected value according to the label in the APF, EPHARM, and Indian brand tablets were about 90.139\%, 96.235\%, and 93.544\%, respectively. Detected values lower than the prescribed value may be due to the possible mass loss of MTZ during preparation or sort of degradation during storage, otherwise originally lower levels of MTZ in the tablets. 
TABLE 2: Percentage recovery of MTZ from pharmaceutical tablets.

\begin{tabular}{lccccc}
\hline Tablet & Present MTZ/mg & Added MTZ/mg & Expected MTZ/mg & Found/mg* & Recovery (\%) \pm \% RSD \\
\hline APF & 0.091 & 0.086 & 0.177 & $0.173 \pm 0.0042$ & $95.604 \pm 2.439$ \\
EPHARM & 0.112 & 0.086 & 0.198 & $0.195 \pm 0.0042$ & $97.321 \pm 2.154$ \\
Indian & 0.114 & 0.086 & 0.200 & $0.195 \pm 0.0040$ & $95.614 \pm 2.054$ \\
\hline
\end{tabular}

* Mean of double measurements.

TABLE 3: Interference study of MTZ with different concentrations of rabeprazole, omeprazole, and tinidazole.

\begin{tabular}{|c|c|c|c|}
\hline Interferent & $\begin{array}{l}\text { Concentration in } \mu \mathrm{M} \text { of the } \\
\text { interferent added to } 35 / \mu \mathrm{M} \text { MTZ }\end{array}$ & Recorded signal $\left(I_{P} / \mu \mathrm{A}\right)$ & Signal change (\%) \\
\hline \multirow{4}{*}{ Rabeprazole } & 0 & 38.19 & - \\
\hline & 117 & 37.68 & 1.335 \\
\hline & 233 & 36.64 & 4.059 \\
\hline & 350 & 36.53 & 4.347 \\
\hline \multirow{4}{*}{ Omeprazole } & 0 & 38.19 & - \\
\hline & 117 & 37.19 & 2.618 \\
\hline & 233 & 36.64 & 4.059 \\
\hline & 350 & 36.53 & 4.347 \\
\hline \multirow{4}{*}{ Tinidazole } & 0 & 38.19 & - \\
\hline & 117 & 40.77 & 6.756 \\
\hline & 233 & 41.79 & 9.426 \\
\hline & 350 & 44.23 & 15.816 \\
\hline
\end{tabular}

The square wave voltammograms for $35 \mu \mathrm{M}$ tablet samples of each brand tablet, each spiked with the same amount of standard MTZ $(100 \mu \mathrm{M})$, were recorded (figures not shown). As can be observed from Table 2, recovery results in the range of $95.374 \%$ to $97.331 \%$ confirmed the potential applicability of the developed method for MTZ analyses in real samples. Relative standard deviation (RSD) of 2.439 which is comparable to elsewhere reported work using UTGE [18] showed the reliability of our result.

To further elaborate the potential applicability of the method, the selectivity of the method for MTZ in the presence of potential interferents was studied. For the interference studies, drugs which could be present in the MTZ tablet (rabeprazole and omeprazole) or have structural similarities with MTZ (tinidazole) were selected. The effect of each selected potential interferent was investigated at various concentrations of the interferents (figure not shown) added to $35 \mu \mathrm{M}$ MTZ. As can be seen from Table 3, the presence of different concentrations of rabeprazole and omeprazole with a fixed concentration of metronidazole did not significantly affect the peak current response for the MTZ and the change in peak current was less than $5 \%$. However, the presence of tinidazole in whatever amount showed positive interference as in the reported works [11].

\section{Conclusion}

Cyclic voltammetric investigation of metronidazole at CPE revealed an irreversible reduction peak over the studied potential window. While the peak potential shift with scan rate confirmed the irreversibility of the reaction, peak potential shift with $\mathrm{pH}$ also indicated the involvement of protons in the reduction process. The calculated kinetic parameters of the reduction of metronidazole at carbon paste electrode are found to be in agreement with the proposed reaction mechanism in literature. Under the optimized solution $\mathrm{pH}$, SWV, and accumulation parameters, carbon paste electrode showed relatively wide linear range with comparable LOD, LOQ, recovery, and selectivity relative to the previously reported works which have used expensive electrodes.

Hence, the developed electrochemical method using the cheapest carbon based electrode can be used as an alternative method for the determination of metronidazole even in a complex matrix system like pharmaceutical formulations.

\section{Competing Interests}

The authors declare that they have no competing interests.

\section{References}

[1] D. I. Edwards, "Nitroimidazole drugs-action and resistance mechanisms I. Mechanisms of action," Journal of Antimicrobial Chemotherapy, vol. 31, no. 1, pp. 9-20, 1993.

[2] P. Verma, V. Namboodiry, S. Mishra, A. Bhagwat, and S. Bhoir, "A stability indicating HPLC method for the determination of Metronidazole using Ecofriendly solvent as mobile phase component," International Journal of Pharmacy and Pharmaceutical Sciences, vol. 5, no. 2, pp. 496-501, 2013.

[3] S. L. Pendland, S. C. Piscitelli, P. C. Schreckenberger, and L. H. Danziger, "In vitro activities of metronidazole and its hydroxy 
metabolite against Bacteroides spp.," Antimicrobial Agents and Chemotherapy, vol. 38, no. 9, pp. 2106-2110, 1994.

[4] G. E. Wild, "The role of antibiotics in the management of Crohn's disease," Inflammatory Bowel Diseases, vol. 10, no. 3, pp. 321-323, 2004.

[5] S. Löfmark, C. Edlund, and C. E. Nord, "Metronidazole is still the drug of choice for treatment of anaerobic infections," Clinical Infectious Diseases, vol. 50, no. 1, pp. S16-S23, 2010.

[6] J. Samuelson, "Why metronidazole is active against both bacteria and parasites," Antimicrobial Agents and Chemotherapy, vol. 43, no. 7, pp. 1533-1541, 1999.

[7] J. L. Mathew, "Effect of maternal antibiotics on breast feeding infants," Postgraduate Medical Journal, vol. 80, no. 942, pp. 196200, 2004.

[8] S. L. Cudmore, K. L. Delgaty, S. F. Hayward-McClelland, D. P. Petrin, and G. E. Garber, "Treatment of infections caused by metronidazole-resistant Trichomonas vaginalis," Clinical Microbiology Reviews, vol. 17, no. 4, pp. 783-793, 2004.

[9] A. Gulaid, G. W. Houghton, O. R. W. Lewellen, J. Smith, and P. S. Thorne, "Determination of metronidazole and its two major metabolites in biological fluids by high pressure liquid chromatography," British Journal of Clinical Pharmacology, vol. 6, no. 5, pp. 430-432, 1978.

[10] E. Ezzeldin and T. M. El-Nahhas, "New analytical method for the determination of metronidazole in human plasma: application to bioequivalence study," Tropical Journal of Pharmaceutical Research, vol. 11, no. 5, pp. 799-805, 2012.

[11] P. Thulasamma and P. Venkateswarlu, "Spectrophotometric method for the determination of metronidazole in pharmaceutical pure and dosage forms," Rasayan Journal of Chemistry, vol. 2, no. 4, pp. 865-868, 2009.

[12] Y. N. Manohara, R. Venkatasha Perumal, R. Revathi Bahlul, and Z. Awen, "Novel and rapid estimation of metronidazole in tablets," Der Pharma Chemica, vol. 2, no. 3, pp. 148-151, 2010.

[13] C. J. Threresa, R. Minju, K. R. Reshma, T. V. Vidya, P. S. Vrinda, and T. N. Vrindha, "Spectrophotometric determination of metronidazole in bulk and dosage form," International Journal of Pharmacy and Pharmaceutical Sciences, vol. 1, no. 1, pp. 11-15, 2014.

[14] M. R. Siddiqui, Z. A. Alothman, and N. Rahman, "Analytical techniques in pharmaceutical analysis: a review," Arabian Journal of Chemistry, 2013.

[15] D. Grieshaber, R. MacKenzie, J. Vörös, and E. Reimhult, "Electrochemical biosensors-sensor principles and architectures," Sensors, vol. 8, no. 3, pp. 1400-1458, 2008.

[16] Y. Wang, H. Xu, J. Zhang, and G. Li, "Electrochemical sensors for clinic analysis," Sensors, vol. 8, no. 4, pp. 2043-2081, 2008.

[17] M. A. La-Scalea, S. H. P. Serrano, and I. G. R. Gutz, "Voltammetric behaviour of metronidazole at mercury electrodes," Journal of the Brazilian Chemical Society, vol. 10, no. 2, pp. 127-135, 1999.

[18] A. Z. Abu Zuhri, S. I. Al-Khalil, and M. S. Suleiman, "Electrochemical reduction of metronidazole and its determination in pharmaceutical dosage forms by D.C. polarography," Analytical Letters, vol. 19, no. 3-4, pp. 453-459, 1986.

[19] A. M. O. Brett, S. H. P. Serrano, I. G. R. Gutz, and M. A. LaScalea, "Voltammetric behavior of metronidazole at different electrodes," Electroanalysis, vol. 9, no. 2, pp. 110-114, 1997.

[20] G. Sahu, "Voltammetric behaviour of metronidazole at a composite polymer membrane electrode," Oriental Journal of Chemistry, vol. 26, no. 1, pp. 81-86, 2010.
[21] Y. Selehattin, E. Baltaoglu, G. Saglikoglu, S. Yagmur, K. Polat, and M. Sadikoglu, "Electroanalytical determination of metronidazole in tablet dosage form," Journal of the Serbian Chemical Society, vol. 78, no. 2, pp. 295-302, 2013.

[22] S. A. Özkan, Y. Özkan, and Z. Şentürk, "Electrochemical reduction of metronidazole at activated glassy carbon electrode and its determination in pharmaceutical dosage forms," Journal of Pharmaceutical and Biomedical Analysis, vol. 17, no. 2, pp. 299305, 1998.

[23] S. Lu, K. Wu, X. Dang, and S. Hu, "Electrochemical reduction and voltammetric determination of metronidazole at a nanomaterial thin film coated glassy carbon electrode," Talanta, vol. 63, no. 3, pp. 653-657, 2004.

[24] Z. Tunay, I. Şahin, and N. Nakiboglu, "Voltammetric determination of boron using cobalt phthalocyanine modified carbon paste electrode," International Journal of Electrochemical Science, vol. 6, no. 12, pp. 6628-6638, 2011.

[25] J. Wang, Analytical Electrochemistry, John Wiley \& Sons, New Jersey, NJ, USA, 3rd edition, 2006.

[26] C. M. A. Brett and A. M. O. Brett, Electrochemistry Principles, Methods, and Applications, Oxford University Press, Oxford, UK, 1st edition, 1993.

[27] A. J. Bard and L. R. Faulkner, Electrochemical Methods, Fundamentals and Applications, John Wiley \& Sons, New York, NY, USA, 2nd edition, 2001.

[28] E. Laviron, "General expression of the linear potential sweep voltammogram in the case of diffusionless electrochemical systems," Journal of Electroanalytical Chemistry, vol. 101, no. 1, pp. 19-28, 1979.

[29] L. Fotouhi, M. Fatollahzadeh, and M. M. Heravi, "Electrochemical behavior and voltammetric determination of sulfaguanidine at a glassy carbon electrode modified with a multi-walled carbon nanotube," International Journal of Electrochemical Science, vol. 7, no. 5, pp. 3919-3928, 2012. 

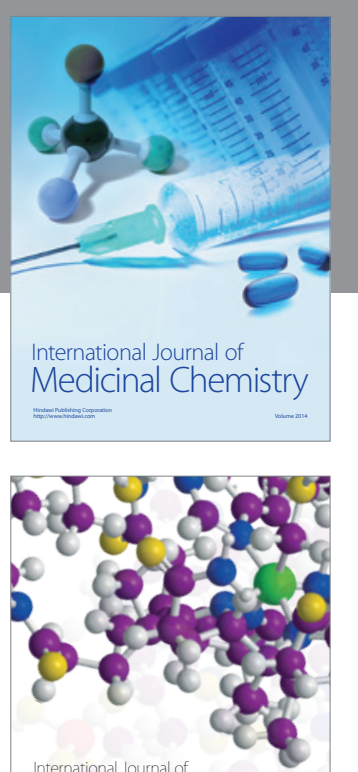

Carbohydrate Chemistry

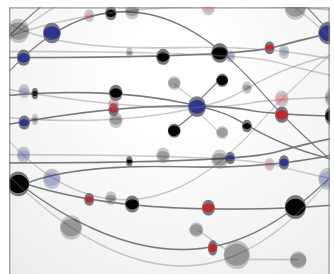

The Scientific World Journal
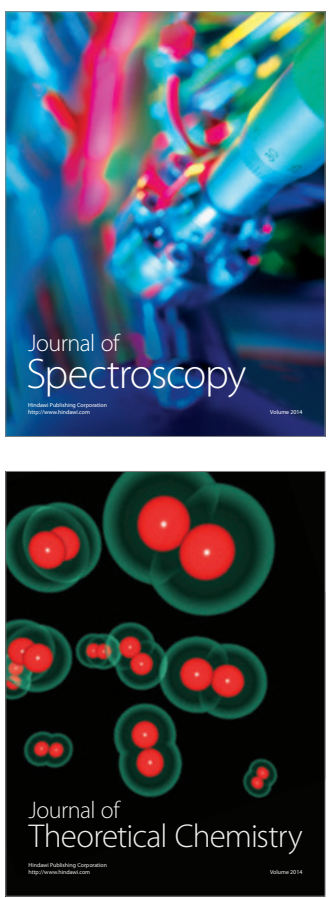
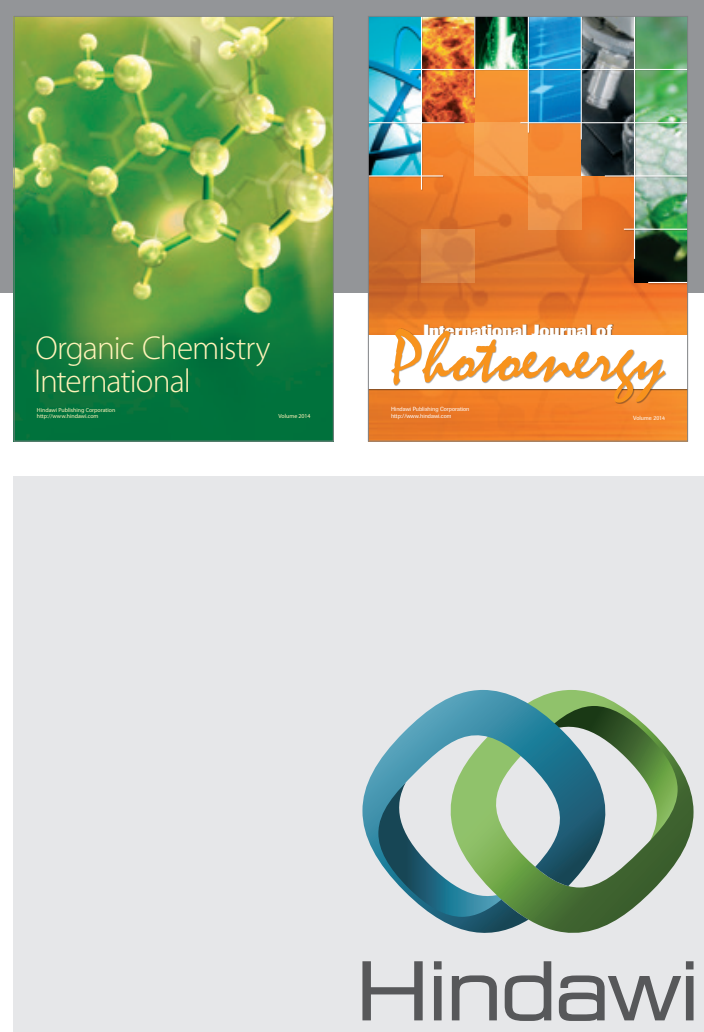

Submit your manuscripts at

http://www.hindawi.com

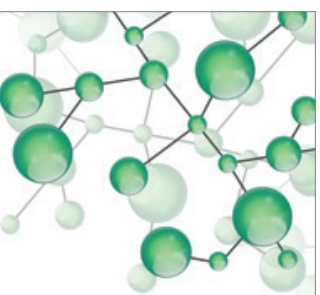

International Journal of

Inorganic Chemistry

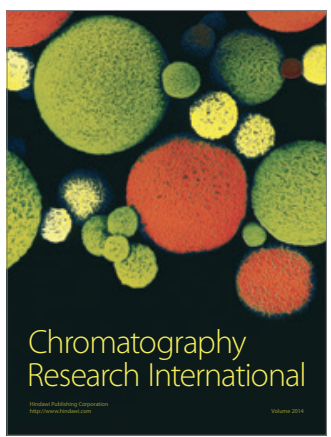

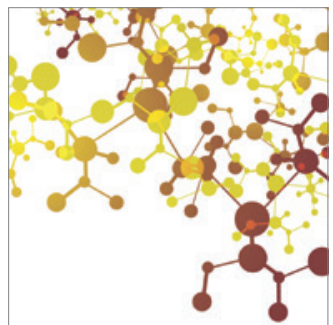

Applied Chemistry
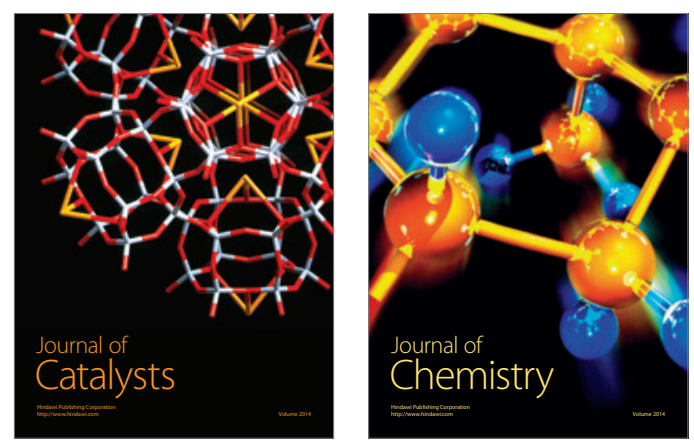
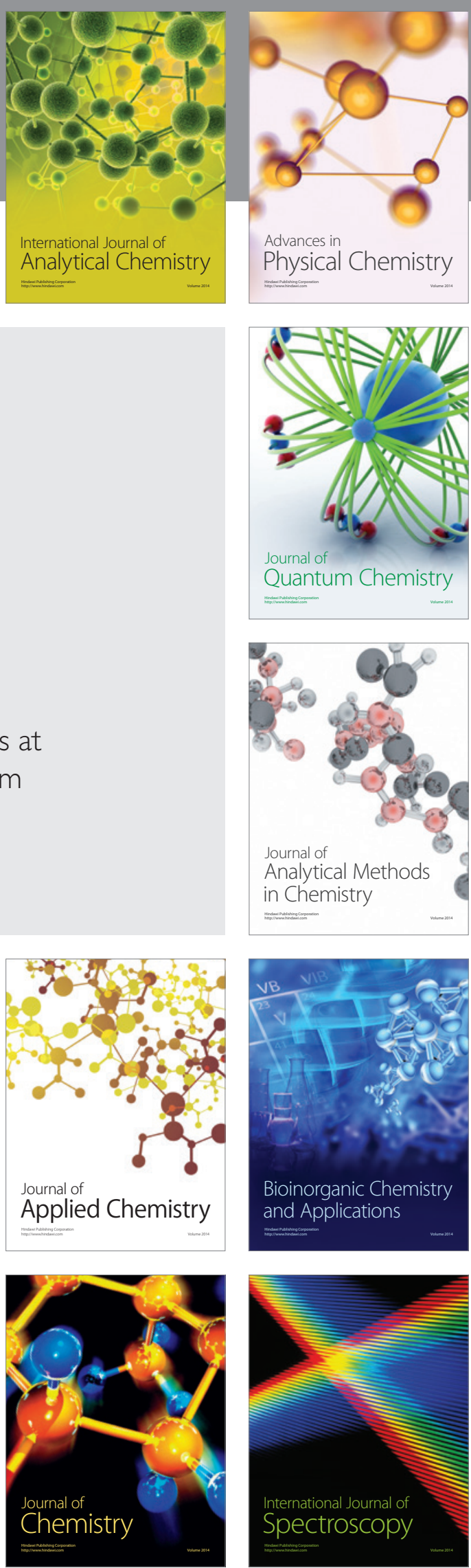